\title{
Pulling the rug out from
}

\section{under the stacks (revisited)}

\author{
By Darrel M. Meinke \\ Dean of Instructional Resources \\ Moorhead State University, Moorhead, Minnesota
}

\section{Another library makes use of the stack-mover for refurbishing.}

$\mathbf{I}_{\mathrm{n}}$ sity began the task of removing asbestos from 30,000 square feet of Livingston Lord Library. At the same time we began the construction of a third and fourth floor of 28,000 square feet, and prepared to totally refurbish the original building of 100,000 square feet.

Early on in the planning for this project it was recognized that this project would require an inordinate amount of book and stack moving. A search for solutions began, and in the July/August issue appeared James Segesta's article, "Pulling the rug out from under the stacks." It served as a catalyst for our director of facilities management, Lester Johnson, who is well known in Minnesota State University circles for his creativity in solving mechanical and technical problems, resulting in major savings to the System.

After a good deal of discussion, examining the varied shelving in the building, and surveying the types of materials housed on the shelves, Johnson called to tell me he had a solution and a stackmover was in the process of being built. I wish I had recorded the actual date, because I consider it something of an historic occasion, but I recall it was early in September that the stack-mover was ready for a test run.

The stack moving system was brought to the library. We selected a $21^{\prime}$ range of double-faced shelving, loaded with bound periodicals, twelve shelves per section, for the test. It took us about 15 minutes to attach the system, after which we elevated the jacks attached to the system. With no complications, the stack cleared the floor, and three of us gingerly applied pressure and without difficulty moved the stack the distance of its length. We then rolled it back and returned it to its original position. Since that day we have moved tens of thousands of volumes and hundreds of stack ranges varying in length from six to thirty feet, all without damage to materials, stacks, or the floor covering.

The system is most comfortably operated by six to eight people when moving ranges that are $21^{\prime}$ or more in length. To illustrate, in order to clear a large area for carpeting, eight students moved twenty-two fully loaded $21^{\prime}$ double-faced periodical ranges in two hours and forty minutes. After the carpet was installed we replaced the stacks in an equal amount of time. The move involved 42.72 hours of person time at $\$ 5 /$ hour, a total cost of $\$ 213.60$. Based on our experience elsewhere in the building project, the same move, assuming the cost of removing the materials to carts or boxes, dismantling and storing the shelving, and then reversing the process would take at the very minimum 262 person-hours at $\$ 5 /$ hour, a total cost of $\$ 1,310$, more than six times the cost.

The system consists of metal racks on large cast- 


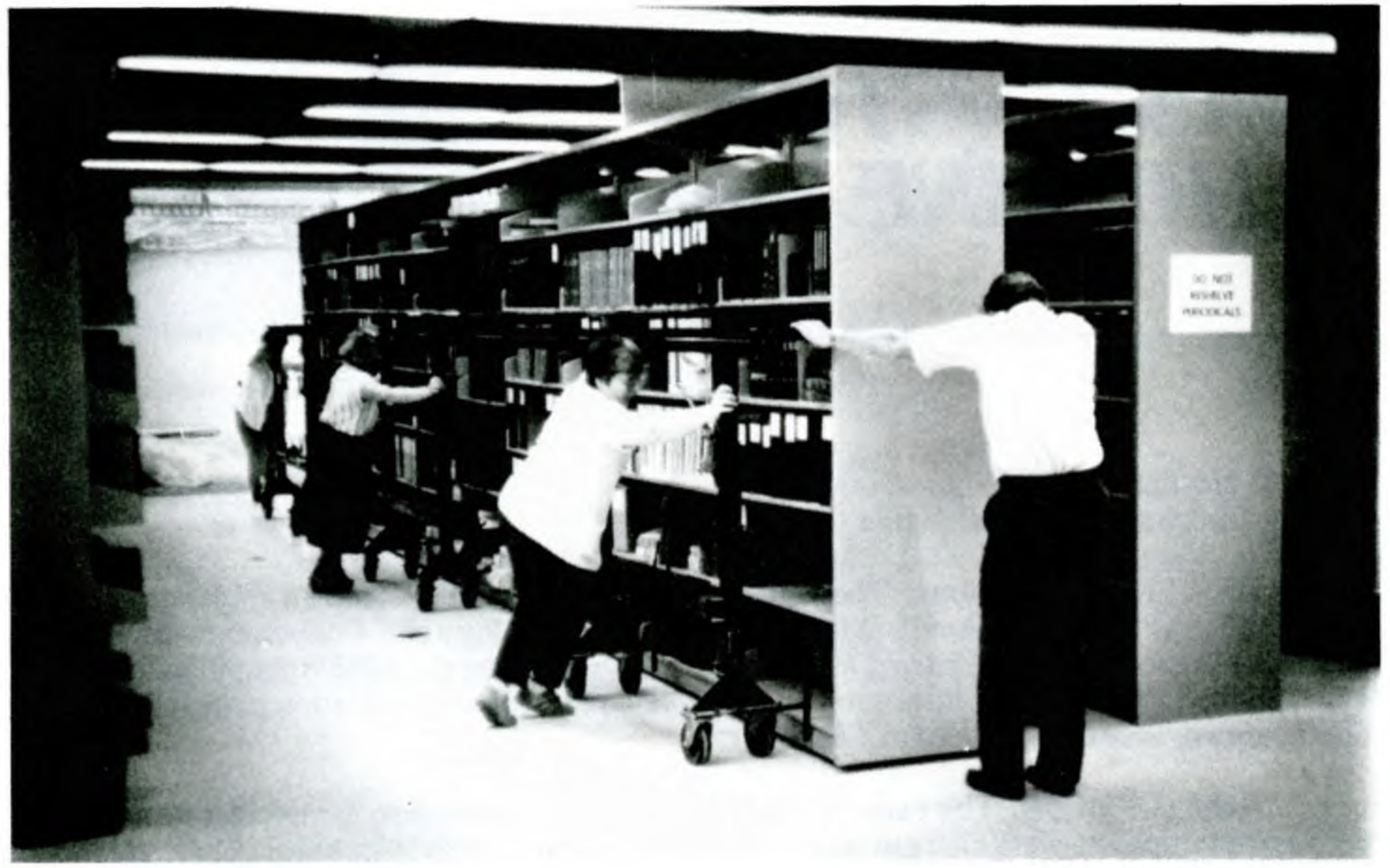

The stack-mover allows for easy shifting of stack ranges.

Each rack is six feet in length. Three of these racks on each side of a double-faced range of stacks, when joined by metal extenders, and metal cross braces attached to each of the uprights of the stacks and resting on the side racks will comfortably move a fully loaded $30^{\prime}$ double-faced range. The lifting power is supplied by two hydraulic jacks attached to each of the side racks. The system requires no prior preparation of the stacks, except for an occasional adjustment of a shelf to allow the cross brace to extend through the stacks comfortably. The stack is lifted from the top. The loader rolls easily on carpet as well as tile. We occasionally used plywood runners over newly installed carpet tile because of the "setting time" required by this type of carpet installation. All of my doubts about the capability of the system disappeared when we moved a $30^{\prime}$ oversize doublefaced range loaded four shelves high with the National Union Catalog a distance of $175^{\prime}$, the full length of the building. Our library is built in $18^{\prime} \times$ $24^{\prime}$ modules, so anything beyond $30^{\prime}$ would become very difficult to navigate.

During several expansion phases of Livingston Lord Library, we have accumulated steel stacks from four major manufacturers, and we moved them all with equal ease and no ill effects to the stacks. We obviously have not solved the problem of moving from floor to floor, neither have we had to cope with doors that were not high enough or wide enough. However, as Johnson pointed out to me when I mentioned the door problem, "It would be cheaper to knock out the door." We know it eliminates the storing of a collection on carts or in boxes, making materials inaccessible to users. It also eliminates the damage to materials almost cer- tain to occur when being handled in the process of moving or storing. Hours and hours of shelfreading are eliminated. With the stack-mover, total recarpeting is the obvious choice. The biggest problem seems to be providing adequate signage to let the user know where the collection "rolled off to today."

Our $\$ 3.4$ million building program was successfully completed eight months ahead of schedule because of outstanding cooperative planning between the architect, Yeater, Hennings and Ruff; the general contractor, John T. Jones Construction Co.; and the owners. We have all agreed, however, that the contribution of the stack-mover played a significant role in keeping construction and library services out of each others way, allowing scheduled projects to move forward without delay.

Johnson is now pursuing the marketing of his innovation. Inquiries for additional information may be addressed to the author.

\section{Correction}

Two errors crept into the profile of Lawrence Dowler published in the March 1988 issue. Dowler served as special assistant to the director of Harvard University Library since 1985, and he will assist the librarian of Harvard College and work closely with senior members of the Public Services Department on the program for implementation of the online catalog. 